\title{
Leisure Activities as a Predictor of Cognitive Decline and Dementia in Old Age
}

\author{
Ana Maria Ribeiro, Sara Monteiro, Anabela Sousa Pereira \\ Department of Education and Psychology, Research Centre Didactics and Technology in Teacher Education, Center for Health \\ Techology and Services Resaerch, University of Aveiro, Aveiro, Portugal \\ Email:ana.maria.ferreira@ua.pt,smonteiro@ua.pt, anabelapereira@ua.pt
}

How to cite this paper: Ribeiro, A.M., Monteiro, S. and Pereira, A.S. (2017) Leisure Activities as a Predictor of Cognitive Decline and Dementia in Old Age. Open Journal of Social Sciences, 5, 254-259. https://doi.org/10.4236/jss.2017.53023

Received: February 22, 2017

Accepted: March 28, 2017

Published: March 31, 2017

Copyright (c) 2017 by authors and Scientific Research Publishing Inc. This work is licensed under the Creative Commons Attribution International License (CC BY 4.0).

http://creativecommons.org/licenses/by/4.0/

\section{cc) (i) Open Access}

\begin{abstract}
Dementia is a growing medical and social problem with a devastating impact on the people affected and their respective families/care-takers. Therefore, having knowledge of the relationship between leisure activities with the dementia framework may be of extreme importance in early preventative diagnosis. In this project, by means of a transversal design, an empirical study was carried out to evaluate the principal effects of leisure in dementia development. The project included the participation of 61 elderly persons, 23 clinically diagnosed with dementia and 38 without a clinical diagnosis of dementia. This research takes into consideration one moment of the evaluation; the information having been gathered using evaluation instruments selected to this effect: Sociodemographic Questionnaire, Mini Mental State Exam, Portuguese Version, and Clinical Dementia Rating, Portuguese Version. From the results, it is highlighted that 1) leisure activities seem to be a protection factor in the development of dementia; and 2) leisure emerges as a predictor variable. The interpretation of the results, as well as their possible implications with regard to prevention and treatment, are discussed in light of the relevant literature.
\end{abstract}

\section{Keywords}

Cognitive Decline, Dementia, Leisure Activities, Old Age

\section{Introduction}

The health of the elderly, real and perceived, is a key aspect when we consider optimal aging. Reference to health problems is a constant problem in interviews and evaluations of the elderly appearing at the top of their concerns. Dementia is among the disorders that most compromise the quality of life of the elderly since it increases the probability of the development of functional incapacity triggering thereby an important public health problem. It overloads families and insti- 
tutions providing care for the elderly as well as public health services.

Dementia constitutes a growing medical and social problem, occurring at all ages, in particular the elderly, and affecting all groups of people, regardless of gender, ethnicity or social class.

Recently, scientific research has recognized that the development and clinical manifestations of dementia can be explained by individual differences occurring not only due to genetic and biological factors, but also because of environmental and social causes (such as physical activity, education, interests, hobbies, among others) - aspects which are part of lived experience since childhood to adulthood [1] [2] [3]. Several epidemiological and biological studies indicate that specific factors acting at different times throughout life, factors which include intellectually stimulating activities, can contribute to an increase of cognitive reserves and, therefore, promote a more efficient functioning of cognitive networks dealing with cerebral pathologies, and delay the onset of clinical manifestations of dementia. These factors include education, hobbies, and leisure activities.

According to several epidemiological studies [4] [5], the adoption of a lifestyle which includes regular participation in cognitive, physical and social leisure activities is associated with a lower cognitive decline in healthy elderly people and may therefore reduce the risk of dementia. Participation in leisure activities, such as reading newspapers, magazines and books, writing, lace and knitting, gardening, board games, social gatherings, physical activity, among others, has been related to better cognitive performance in old age.

High levels of participation in these activities have been associated with better performance on memory tests as well as in fluid and crystallized intelligence tests [6], indicating lower decline rates in these cognitive functions over a seven-year range [7]. Moreover, leisure activities in general have been associated with higher levels of cognitive performance and a slower rate of cognitive decline in speed, incidental evocation, figure naming, and verbal fluency measurements over a six-year range [8]. Furthermore, studies investigating the relationship between leisure activities in general and the risk of subsequent dementia showed that regular participation in these activities is directly associated with a lower risk of dementia [9]. Another study [10] also showed that individuals who participated considerably less in leisure activities were more likely to develop Alzheimer's disease.

In this context, knowledge of the impact of the relationship between leisure activities and dementia may be extremely important to help prevent dementia. Thus, according to the aforementioned precepts, the main aim of this study is to analyze the possible association between leisure activities in the development of dementia. The specific objectives of our study are: to examine the role of leisure activities on the onset of dementia; and to evaluate the predictive effects of leisure activities on the development of dementia.

\section{Method}

\subsection{Participants}

We present an empirical investigation with 61 elderly people, 23 with clinical 
diagnosis of dementia and 38 without clinical diagnosis of dementia, in which the main effects of leisure on the development of dementia were evaluated. Of the clinical group, $43.5 \%$ had Alzheimer's disease, $4.3 \%$ vascular dementia and $52.2 \%$ senile dementia. Also within this group, $52.2 \%$ were in a mild stage of dementia, $34.8 \%$ in the moderate stage and $8.7 \%$ in the severe stage.

Regarding leisure activities, the majority of the participants (76.9\%) are involved in different leisure activities: cognitive activities (such as reading books, magazines and newspapers, watching news, filmsand some scientific programs), physical (such as swimming and gymnastics) or social.

\subsection{Instruments}

This study includes only one moment of evaluation. The information was collected from the following evaluation tools selected to that effect: socio-demographic questionnaire, the Mini Mental State Exam-MMSE [11], Portuguese version [12] and Clinical Dementia Rating-CDR [13], Portuguese version [14].

\subsection{Procedure}

In order to carry out thisstudy, to haveaccess to this population, we first decided to contact an institution to support the elderly, more specifically, a nursing home. In this context, we have chosen a qualified institution in its services and sensitive to the needs of research in the area of gerontology.

On the other hand, due to the interest of some volunteers of the general population to take part of our study, secondly, we choose those participants who met the required criteria for this study.

The study sample consisted of a clinical group and a control group. Selection of the first group of participants was performed according to the following criteria: age equal to or greater than 65 years of age, the existence of a clinical diagnosis of dementia and the absence of mental disturbance. On the other hand, selection of the participants who constituted the second group was made taking into consideration the following criteria: age equal to or greater than 65 years of age, absence of clinical diagnosis of dementia and absence of mental disturbance.

In the statistical treatment of data, the Statistical Package for the Social Sciences (SPSS), version 20, was used in order for us to be able make the necessary calculations for the descriptive and inferential statistics.

\section{Results}

Table 1 shows the relationship between leisure activities and the development of

Table 1. Relationship between leisure activities and the development of dementias.

\begin{tabular}{cccc}
\hline & & Leisure activities & \\
\hline & $\mathrm{M}(\mathrm{DP})$ & $\mathrm{M}(\mathrm{DP})$ & Mann-Whitney \\
\hline \multirow{2}{*}{ CDR } & Yes $(\mathrm{n}=36)$ & $\mathrm{No}(\mathrm{n}=25)$ & $\mathrm{Z}=-4.80^{* * *}$
\end{tabular}

${ }^{* * *} \mathrm{p} \leq 0.001$ 
dementia. The analysis of Table 1 shows that there are statistically significant differences between the different groups of leisure activities at the level of dementia development and also that the degree of dementia is lower for individuals who have more leisure activities.

We can verify through the analysis of Table 2 that leisure functions as a predictive variable for the development of dementia (since it is a statistical significant variable) where $40 \%$ of the degree of dementia variation is explained by the variation of these leisure activities.

Since the $\chi 2$ statistic, designated as Pearson's Chi-square, is currently used to measure the discrepancies between observed and expected variables, and because low values indicate the presence of an adequate adjustment, we observed in Table 3 that, although not statistically significant, we may induce that the quality of adjustment of the selected model is high.

\section{Discussion}

Our study indicates the existence of a statistically significant relationship between leisure and dementia. Similar studies [15] [16] have shown a protective effect of leisure activities for the development of dementia, which meets also the results of our study. One of the explanatory hypotheses for this association is that it is possible that involvement in several leisure activities throughout life will tend to trigger a more efficient functioning of cognitive networks and therefore provide a cognitive reserve that may delay the onset of clinical manifestations of dementia [5].

These results are important because they demonstrate that environmental stimulation affects organisms both at the cerebral and cognitive levels and thus support the hypothesis that mentally stimulating activities throughout life may produce cerebral organic changes and in turn have beneficial effects on cognitive aging. These organic changes may constitute a physiological basis for beneficial cognitive functioning through the promotion of brain plasticity throughout life. [17] Thus, leisure activities, enacted throughout life, may function as protective variables of cognitive decline and, later, dementia.

Finally, the study of the relationship between cognitive performance and leisure

Table 2. Predictive effect of leisure activities.

\begin{tabular}{cccccc}
\hline & Model Fitting Criteria & \multicolumn{2}{c}{ Likelihood Ratio Tests } & \multicolumn{2}{c}{ Pseudo R-Square } \\
\hline Effect & -2 Log Likelihood & Chi-Square & df & Sig. & Cox and Snell \\
\hline Leisure & 48.74 & 31.53 & 4 & $0.000^{* * *}$ & 0.40 \\
\hline
\end{tabular}

${ }^{* * *} \mathrm{p} \leq 0.001$.

Table 3. Goodness-on-fit test.

\begin{tabular}{cccc}
\hline \multicolumn{5}{c}{ Goodness-of-Fit } & & \\
\hline & Chi-square & df. & Sig. \\
\hline Pearson & 0.07 & 24 & 1.00 \\
\hline
\end{tabular}


activities, along with the influence of other variables such as age and gender, may help determine the sources and nature of current cognitive performance in the elderly, and in a sense, may also be the fundamental component of cognitive reserve capacity. Therefore, we think it would make sense in future research work to try to better understand the influence of leisure, social, cognitive and physical activities in the development of dementia and, moreover, to evaluate more rigorously the influence of each of these activities.

\section{References}

[1] Fratiglioni, L., Grut, M., Forsell, Y., et al. (1991) Prevalence of Alzheimer's Disease and Other Dementias in an Elderly Urban Population: Relationship with Age, Sex, and Education. Neurology, 41, 1886-1892. https://doi.org/10.1212/WNL.41.12.1886

[2] Scarmeas, N. and Stern, Y. (2003) Cognitive Reserve and Lifestyle. Journal of Clinical and Experimental Neuropsychology, 25, 625-633. https://doi.org/10.1076/jcen.25.5.625.14576

[3] Valenzuela, M.J. and Sachdev, P. (2006) Brain Reserve and Dementia: A Systematic Review. Psychological Medicine, 36, 441-454. https://doi.org/10.1017/s0033291705006264

[4] Fratiglioni, L. and Wang, H.X. (2007) Brain Reserve Hypothesis in Dementia. Journal of Alzheimer's disease, 12, 11-22.

[5] Polidori, M.C., Nelles, G. and Pientka, L. (2010) Prevention of Dementia: Focus on Lifestyle. International Journal of Alzheimer's Disease, 2010, 1-9. https://doi.org/10.4061/2010/393579

[6] Christensen, H., Korten, A., Jorm, A.F., Henderson, A.S., Scott, R. and Mackinnon, A.J. (1996) Activity Levels and Cognitive Functioning in an Elderly Community Sample. Age Ageing, 25, 72-80. https://doi.org/10.1093/ageing/25.1.72

[7] Mackinnon, A., Christensen, H., Hofer, S.M., Korten, A.E. and Jorm, A.F. (2003) Use It and Still Lose It? The Association between Activity and Cognitive Performance Established Using Latent Growth Techniques in a Community Sample. $A g$ ing Neuropsychology Cognition, 10, 215-229. https://doi.org/10.1076/anec.10.3.215.16451

[8] Newson, R.S. and Kemps, E.B. (2005) General Lifestyle Activities as a Predictor of Current Cognition and Cognitive Change in Older Adults: A Cross-Sectional and Longitudinal Examination. Journals of Gerontology Series B: Psychological Sciences and Social Sciences, 60, 113-121. https://doi.org/10.1093/geronb/60.3.p113

[9] Fabrigoule, C., Letenneur, L., Dartigues, J.F., Zarrouk, M., Commenges, D. and Barberger-Gateau, P. (1995) Social and Leisure Activities and Risk of Dementia: A Prospective Longitudinal Study. Journal of the American Geriatrics Society, 43, 485-490. https://doi.org/10.1111/j.1532-5415.1995.tb06093.x

[10] Kondo, K., Niino, M. and Shido, K. (1994) A Case-Control Study of Alzheimer's Disease in Japan-Significance of Life-Styles. Dementia, 5, 314-326. https://doi.org/10.1159/000106741

[11] Folstein, M.F., Folstein, S. and McHugh, P.R. (1975) Mini-Mental State: A Practical Method for Grading the Cognitive State of Patients for the Clinician. Journal of Psychiatric Research, 12, 189-198. https://doi.org/10.1016/0022-3956(75)90026-6

[12] Guerreiro, M., Silva, A.P., Botelho, A., Leitão, O., Castro-Caldas, A. and Garcia, C. (1994) Adaptação à população portuguesa da tradução do Mini Mental State Examination (MMSE). Revista Portuguesa de Neurologia, 1, 9-10. 
[13] Morris, J. (1993) The Clinical Dementia Rating (CDR): Current Version and Scoring Rules. Neurology, 43, 2412-2414. https://doi.org/10.1212/WNL.43.11.2412-a

[14] Garrett, C., Santos, F., Tracana, I., Barreto, J., Sobral, M. and Fonseca, R. (2008) Avaliação clínica da demência-Tradução em português. In: Mendonça, A. and Guerreiro, M., Eds., Escalas e Testes na Demência, Grupo de Estudos de Envelhecimento Cerebral e Demência, Lisboa, 17-32.

[15] Scarmeas, N., Levy, G., Tang, M.X., Manly, J. and Stern, Y. (2001) Influence of Leisure Activity on the Incidence of Alzheimer's Disease. Neurology, 57, 2236-2242. https://doi.org/10.1212/WNL.57.12.2236

[16] Simons, L.A., Simons, J., McCallum, J. and Friedlander, Y. (2006) Lifestyle Factors and Risk of Dementia: Dubbo Study of the Elderly. Medical Journal of Australia, 184, 68-70.

[17] Carret, N.L., Lafont, S., Letenneur, L., Dartigues, J.F. and Mayo, W. (2003) The Effect of Education on Cognitive Performances and Its Implication for the Constitution of the Cognitive Reserve. Developmental Neuropsychology, 23, 317-337. https://doi.org/10.1207/S15326942DN2303_1

\section{Scientific Research Publishing}

\section{Submit or recommend next manuscript to SCIRP and we will provide best} service for you:

Accepting pre-submission inquiries through Email, Facebook, LinkedIn, Twitter, etc. A wide selection of journals (inclusive of 9 subjects, more than 200 journals) Providing 24-hour high-quality service

User-friendly online submission system Fair and swift peer-review system Efficient typesetting and proofreading procedure Display of the result of downloads and visits, as well as the number of cited articles Maximum dissemination of your research work

Submit your manuscript at: http://papersubmission.scirp.org/ Or contact jss@scirp.org 